\section{Psychiatry in} pictures
R.H.S. Mindham (iD

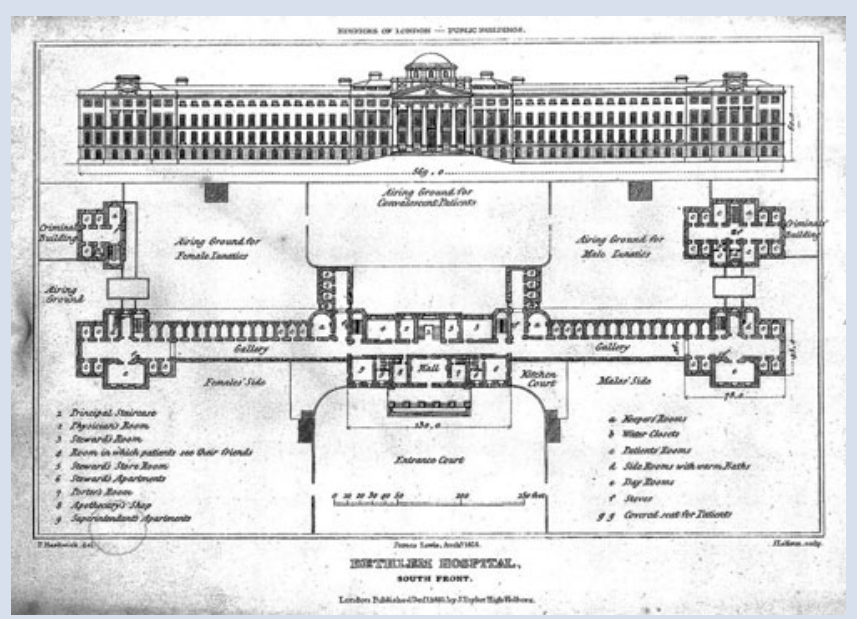

Fig. 1 Bethlem Royal Hospital at Saint George's Fields, Lambeth, 1815. Used by courtesy of Wikimedia Commons, Lambe Wellcome L0011831.

The hospital's building at Moorfields had been neglected and had suffered from the marshy ground on which it had been built. The Governors recognised that new accommodation was needed and, with financial assistance from the Government, decided to move to a new site at St George's Fields, in the London borough of Lambeth. In 1810 an architectural competition was established and proposals invited.

At the time a number of individuals and public bodies were examining ways of providing accommodation for persons suffering from mental illness. They included: Jeremy Bentham the philosopher; the Tuke family, social reformers in York; William Stark in Glasgow, James Bevans at Guy's Hospital, London, John Carr in York and Richard Ingleman in Nottingham, all architects; and Andrew Duncan and John Storer, physicians, in Edinburgh and Nottingham respectively. Bethlem Hospital had achieved great notoriety at the end of the 18th century for its harsh treatment of inmates. The Governors were accused of overseeing neglect, disregard of patients interests and brutality, which led to the establishment of the Parliamentary Inquiry into Madhouses. It was in this setting that the planning of the new hospital was conducted.

The Judges of the proposals were: the hospital architect James Lewis, who had been appointed in 1793; George Dance the younger, architect for the the rebuilding of St Luke's Hospital, London, 1782-1789, and Samuel Pepys cockerell. The judges awarded premiums for the best three proposals. A current in-patient, James Tilley Matthews, submitted plans; these proposals impressed the judges, who awarded him a special premium in recognition of his work. He had been admitted to Bethlem in 1797 suffering from a delusional illness but had shown himself to possess substantial intellectual powers. None of the proposals was adopted and the Governors instructed Lewis to prepare plans of his own incorporating the best features of the plans submitted. Building began in 1812 and the new hospital was opened in 1815.

The building Lewis designed was similar to the Moorfields Bethlem it replaced. There were two storeys together with a basement and attics. At the centre was a prominent administrative block with wards extending on each side terminating in pavilions. Patients were accommodated in gallery wards with single rooms opening onto a wide corridor. The entrance to the hospital was beneath an impressive portico. The administrative block was surmounted by a low dome which held the chapel (Fig. 1). In 1835 Sidney Smirke added substantial wards blocks at each end extending behind the façade. The additions provided single rooms on each side of a central corridor and were used to accommodate 'criminal lunatics' until the opening of Broadmoor Hospital in 1863. In 1844-1846, Smirke added a higher dome to the administrative block, which enlarged the chapel and improved the appearance of the building.

The building at St George's Fields remained in use until 1930, when the hospital moved to a new site in Beckenham, Kent. The property at St George's Fields was bought by the press baron Lord Rothermere, who presented it to the London County Council as a park in memory of his mother. Later, the wings were demolished and the central part of the building became the Imperial War Museum.

(C) The Author(s), 2021. Published by Cambridge University Press on behalf of the Royal College of Psychiatrists 